FACTA UNIVERSITATIS

Series: Mechanical Engineering Vol. 17, N² 2, 2019, pp. 161 - 168

https://doi.org/10.22190/FUME190330023K

Original scientific paper

\title{
IMPACT OF INDENTOR SLIDING VELOCITY AND LOADING REPETITION FACTOR ON SHEAR STRAIN AND STRUCTURE DISPERSION IN NANOSTRUCTURING BURNISHING
}

\author{
Viktor P. Kuznetsov ${ }^{1}$, Andrey S. Skorobogatov ${ }^{1}$, Vladimir G. Gorgots ${ }^{2}$ \\ ${ }^{1}$ Ural Federal University, Russia \\ ${ }^{2}$ Kurgan State University, Russia
}

\begin{abstract}
The article probes into a relationship of the shear strain intensity and the shear strain rate in the surface layer and the sliding velocity of a spherical indentor and its loading repetition factor. It brings forward an experimental procedure to evaluate the shear strain intensity and rate by analyzing the geometrical parameters of the bulge of plastically edged metal and the thickness of the shifted layer relative to different sliding velocities and feed rates.
\end{abstract}

Key Words: Surface Layer, Nanostructuring Burnishing, Spherical Indentor, Severe Plastic Shear Deformation, Sliding Velocity, Loading Repetition Factor

\section{INTRODUCTION}

Burnishing implementation as a surface plastic deforming technique has been widely applied for finishing surface layers of precision parts on metal-cutting machines. Application of burnishing brings about adequate dimensional accuracy; it also succeeds in decreasing the height of microprofile irregularities by several times, increasing the surface layer microhardness and creating a substantial extent of compressive residual stresses.

A number of authors [1-7] have studied finishing and hardening burnishing without taking into consideration the possibility of forming nanocrystalline structures. To promote burnishing the papers [8-16] bring into the foreground a finishing technique for forming a nanocrystalline structure in the surface layer, which puts to use the method of severe plastic shear deformation (SPD), named nanostructuring burnishing (NSB). The NSB technique makes it possible to impart unique performance attributes to the surface layer,

Received March 30, 2019 / Accepted June 02, 2019

Corresponding author: Viktor P. Kuznetsov

Ural Federal University, Institute of New Materials and Technologies, 19 Mira Street, Ekaterinburg 620002, Russia

E-mail: wpkuzn@mail.ru 
and it can be implemented in the process of machining on modern lathes and machining centers.

However, the influence of the indentor sliding velocity and the loading repetition factor on the evolution of SPD as well as the formation of the nanocrystalline structure in the thin surface layer have not been studied in depth.

Zhao et al. [17] study the formation of a gradient nano/microstructured layer in a sample of pure copper; the layer is produced by severe plastic deformation with roller burnishing (SPRB). The experimental results showed that the gradient layer had a thickness over $100 \mu \mathrm{m}$. The significantly increased hardness close to the surface resulted predominantly from decreasing the grain sizes. The nano-dimension grains were randomly oriented; most boundaries turned out to be low angle ones. It was in the nanostructure that dislocation activities prevailed, accompanied by rotating grains in the local area.

Roland et al. [18] describe a research study of the influence that a nanocrystalline surface layer exerts on fatigue properties of a 3161 stainless steel; this layer is obtained by applying mechanical attrition treatment to the surface (SMAT).

Qualitative surface layers containing ultra-fine grains or nano-grains can be formed in the process of cryogenic burnishing of an AI 7050-T7451 alloy with a roller tool [19]; it can be achieved by means of applied severe plastic deformation and dynamic recrystallization (DRX) inherent in it.

The article compares dry and cryogenic burnishing. It shows that refined layers containing nano-grains come into being in the surface that undergoes cryogenic treatment. The average hardness at a depth of $200 \mu \mathrm{m}$ is higher after cryogenic burnishing than after dry burnishing by $9.5 \%, 17.5 \%$ and $24.8 \%$ at a rate of 25,50 and $100 \mathrm{~m} / \mathrm{min}$, respectively.

A number of authors [20-26] describe the research that has been done into effects of severe plastic deformation parameters on the dispersion of grain structures in structural materials. They show that for the formation of a nanocrystalline structure it is necessary that the shear strain intensity exceeding 2 and the shear strain rate being above $10^{2} \mathrm{~s}^{-1}$ should be ensured.

The present research aims at establishing a relationship of the indentor sliding velocity and an integral parameter of loading repetition factor and the shear strain intensity and shear strain rate in the surface layer of $\mathrm{X} 20 \mathrm{Cr} 13$ steel and the dispersion degree of the formed nanocrystalline structure.

\section{MATERIALS AND METHODS}

An experiment-calculated procedure is brought forward to determine the plastic shear strain intensity and rate in the surface layer. The procedure is based on measuring the length of the bulge, which is edged by the tool, applying 3D profilometry and the depth, to which shear strain propagates, by examining the deformed surface layer with scanning microscopy (Fig.1).

Material shear strain $\gamma$ can be determined as a tangent of the shear angle or as a ratio of length $l_{r}$ of the edged metal bulge to thickness $h_{s}$ of the sheared layer:

$$
\gamma=\operatorname{tg} \varphi=l_{r} / h_{s}
$$

The true plastic shear strain is calculated with the following relation:

$$
\varepsilon=\ln (1+\gamma)=\ln \left(1+l_{r} / h_{s}\right)
$$




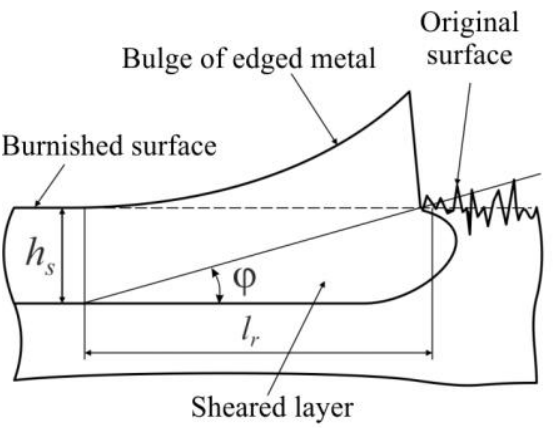

a)

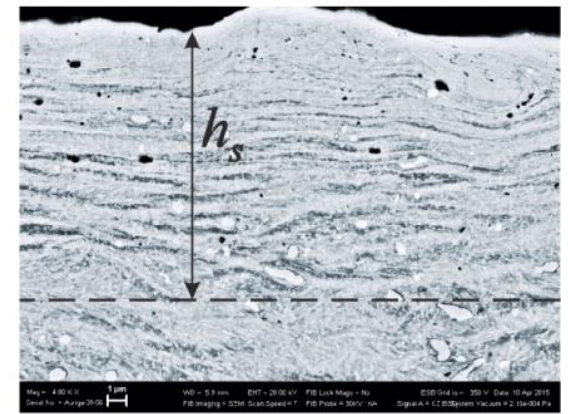

b)

Fig. 1 Location of relative deformation (a) and scanning microscopy of the deformed layer (b)

The value of the true shear strain makes it possible to determine a relation of the mean strain rate to indentor sliding velocity $v_{b}$ and loading repetition factor $n_{c}$ relative to the elementary volume in the material.

The duration of a single-time action of the indentor on the elementary volume is determined with a relation of contact spot length $a_{\mathrm{c}}$ to sliding velocity $v_{b}$ :

$$
t_{1}=a_{c} / v_{b}
$$

The contact spot length value was determined by measuring width of single path of indenter made with a giving burnishing force as shown in [14]. The resulting spot length value is $370 \pm 6 \mu \mathrm{m}$.

As the tool is fed, generally the indentor acts upon the elementary volume several times. To take the number of these actions into consideration V.P. Kuznetsov's paper [14] introduces an integral parameter of loading repetition factor $n_{c}$, which is determined as follows:

$$
n_{c}=a_{c} / f_{b}
$$

The total deformation time for $n_{c}$ of the indentor's actions is found as follows:

$$
t_{t}=t_{1} n_{c}=\frac{a_{c} n_{c}}{v_{b}}
$$

Thus, the mean shear strain rate in nanostructuring burnishing of the surface layer can be calculated in the following way:

$$
\dot{\varepsilon}=\frac{\gamma}{t_{t}}=\frac{v_{b} \gamma}{a_{c} n_{c}}
$$

Having found the value of accumulated edged material bulge $l_{r a}$ and shifted layer thickness $h_{s}$, it is now possible to evaluate accumulated shear strain intensity $\varepsilon$.

To perform the present experiment-calculated procedure a scheme for burnishing circular paths on a flat sample with a high-precision stopping of the tool (Fig. 2, a) is proposed. These kinematics of the tool lead to forming an accumulated bulge of plastically shifted material at the end of the path (Fig. 2, b). 


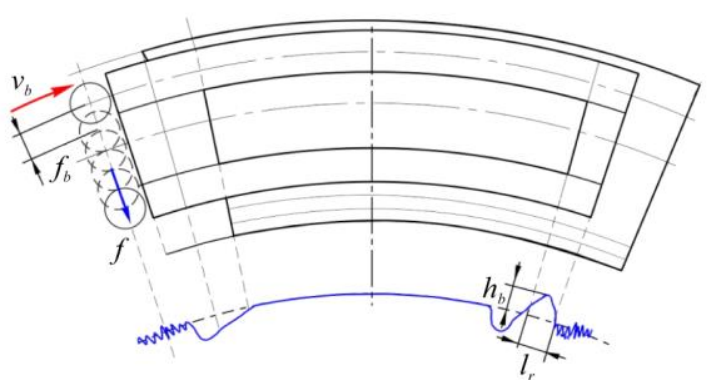

a)

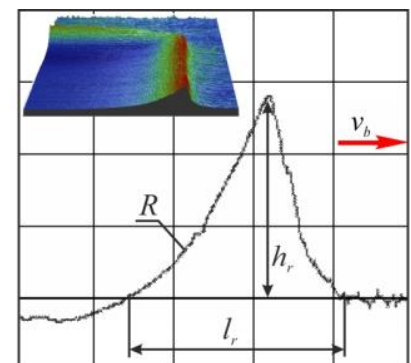

b)

Fig. 2 Burnishing a path with a high-precision stopping (a) for forming an accumulated bulge of plastically edged material (b)

The experimental study was done by machining X20Cr13 steel samples with a $2 \mathrm{~mm}$ radius ASPM-3 polycrystalline diamond (PCD) indentor, the burnishing force being $F_{b}=$ $340 \mathrm{~N}$. The paths were $10 \mathrm{~mm}$ wide and $70 \mathrm{~mm}$ long; three different feed rates were applied $f_{b}=0.06,0.04$ and $0.02 \mathrm{~mm} / \mathrm{rev}$ at sliding velocities $v_{b}=3,6,8,11,14,20$ and $26 \mathrm{~m} / \mathrm{min}$. At these feed rates the loading repetition factor was, respectively, $n_{c}=4.2,6.3$ and 12.6. In this manner, within the framework of a full factorial experiment 21 paths were machined with a unique combination of feed and velocity parameters $f_{b}$ and $v_{b}$. Machining was done on an OKUMA MA600BII machining center.

Geometrical parameters of the bulges produced at each path were studied by optical 3D profilometry on a WYCO NT1100 profilometer. After it, a cross-section metallographic sample was prepared from the middle of each path; these samples were examined by scanning electron microscopy with a Zeiss AURIGA CrossBeam to estimate the thickness of the sheared layer. The structural analysis was done by transmission electron microscopy with a JEOL JEM 2100. The foils were taken from the surface in the middle of each path.

\section{RESULT AND DISCUSSIONS}

On the basis of the results obtained by optical 3D profilometry and scanning electron microscopy (Fig. 3) the sought values of the plastically edged metal bulge length and the sheared layer thickness (Table 1) were found.

The results thus acquired show that as the sliding velocity rises to $11 \mathrm{~m} / \mathrm{min}$, an increase of the accumulated bulge length and the sheared layer thickness regardless of the loading repetition factor can be observed. At the same time, a further increase of the velocity leads to a reverse effect. What is more, the maximum thickness of the sheared layer practically does not correlate with the loading repetition factor and remains within the range from 6.29 to $6.63 \mu \mathrm{m}$. Meanwhile, the length of the accumulated bulge of plastically edged material grows significantly when the loading repetition factor is increased from $272 \mu \mathrm{m}$ at $n_{c}=4.2$ to $348 \mu \mathrm{m}$ at $n_{c}=12.5$.

Inserting the results of the measurements in (2), (3) and (6), the relations of the plastic shear strain intensity and the plastic shear strain rate in the surface layer of X20Cr13 steel were found (Fig. 4). 


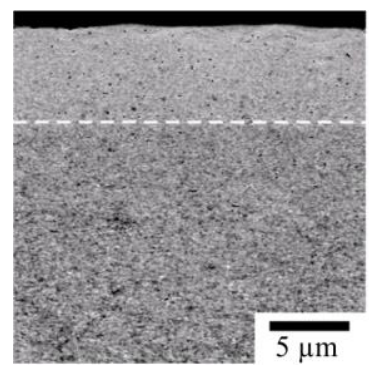

a) $v_{b}=11 \mathrm{~m} / \mathrm{min}$

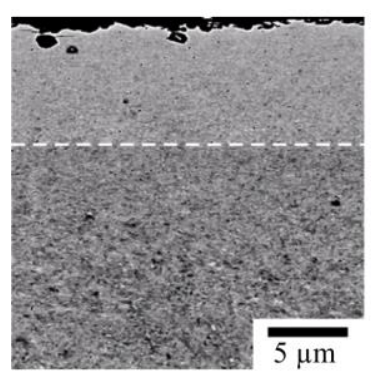

d) $v_{b}=20 \mathrm{~m} / \mathrm{min}$

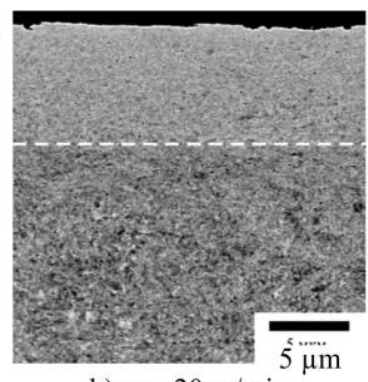

b) $v_{b}=20 \mathrm{~m} / \mathrm{min}$

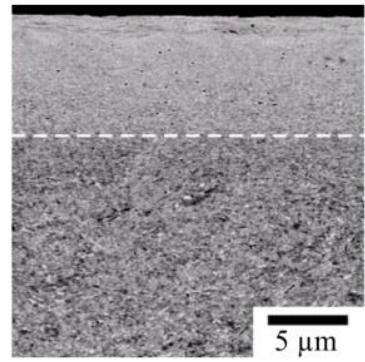

e) $v_{b}=11 \mathrm{~m} / \mathrm{min}$

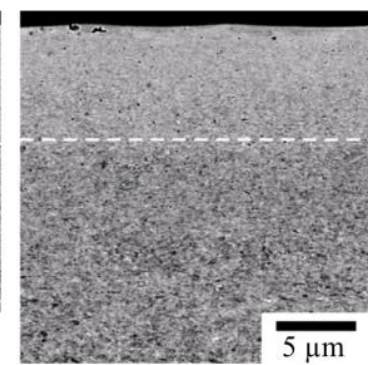

c) $v_{b}=11 \mathrm{~m} / \mathrm{min}$

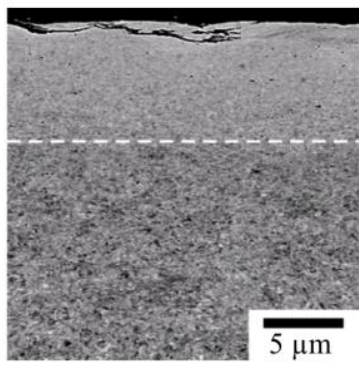

f) $v_{b}=20 \mathrm{~m} / \mathrm{min}$

Fig. 3 Scanning electron microscopy of the surface layer in the paths produced at loading repetition factors of $4.2(\mathrm{a}, \mathrm{b}) ; 6.3(\mathrm{c}, \mathrm{d})$ and $12.5(\mathrm{e}, \mathrm{f})$.

Table 1 Results of measurements

\begin{tabular}{ccccccc}
\hline Sliding & \multicolumn{3}{c}{$n_{c}=4.2$} & \multicolumn{3}{c}{$n_{c}=6.3$} \\
velocity & Bulge length & Layer thickness & Bulge length Layer thickness Bulge length Layer thickness \\
$v_{b}, \mathrm{~m} / \mathrm{min}$ & $l_{r}, \mu \mathrm{m}$ & $h_{s}, \mu \mathrm{m}$ & $l_{r}, \mu \mathrm{m}$ & $h_{s}, \mu \mathrm{m}$ & $l_{r}, \mu \mathrm{m}$ & $h_{s}, \mu \mathrm{m}$ \\
\hline 3 & 40 & 5.1 & 48 & 3.24 & 81 & 3.66 \\
6 & 78 & 5.1 & 42 & 5.54 & 59 & 5.22 \\
8 & 229 & 5.75 & 183 & 5.58 & 174 & 5.65 \\
11 & 272 & 6.29 & 277 & 6.47 & 348 & 6.63 \\
14 & 204 & 6.35 & 202 & 6.42 & 227 & 5.87 \\
20 & 179 & 5.99 & 165 & 5.76 & 205 & 5.7 \\
26 & 175 & 6.04 & 169 & 6.08 & 201 & 6.01 \\
\hline
\end{tabular}

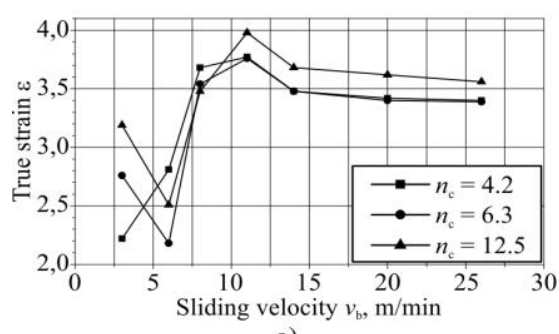

a)

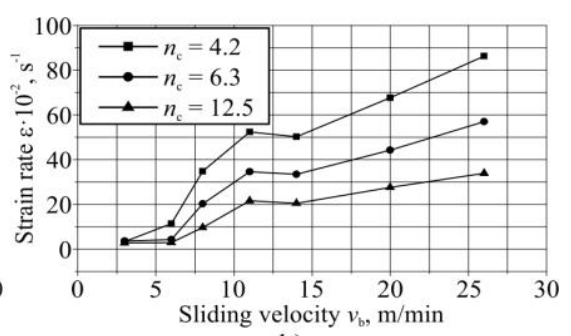

b)

Fig. 4 Relation of the plastic shear strain intensity (a) and the plastic shear strain rate (b) to the sliding velocity when burnishing at feed rates $f_{b}=0.02 \mathrm{~mm} / \mathrm{rev}\left(n_{c}=12.5\right)$, $0.04 \mathrm{~mm} / \mathrm{rev}\left(n_{c}=6.3\right)$ and $0.06 \mathrm{~mm} / \mathrm{rev}\left(n_{c}=4.2\right)$ 
The maximum shear strain intensity $\varepsilon=3.75 \ldots 4$ is obtained when burnishing is done at an indentor sliding velocity of $11 \mathrm{~m} / \mathrm{min}$. At lower velocities the shear strain intensity decreases considerably. At the same time, raising the velocity leads to stabilizing the shear strain intensity at 3.4...3.6. These results turn out to agree well with the experimental data acquired in the papers [14] which describe a similar correlation of the sliding velocity to the microhardness in the surface layer. Besides, the values of the shear strain intensity are confirmed by mathematic simulation presented in the paper [12]. Another conclusion can be drawn that at higher sliding velocities a surface layer shear strain comparable in regard to its intensity may be obtained at substantially higher shear strain rates.

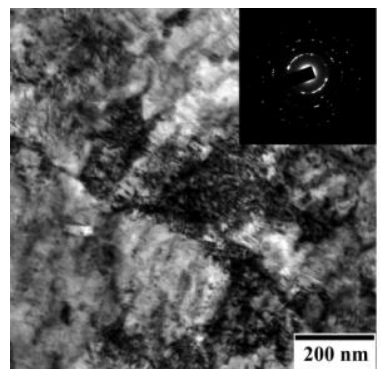

a) $v_{b}=6 \mathrm{~m} / \mathrm{min}$

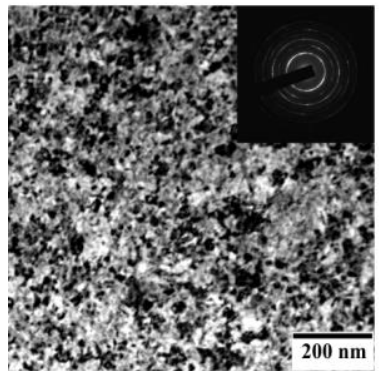

d) $v_{b}=6 \mathrm{~m} / \mathrm{min}$

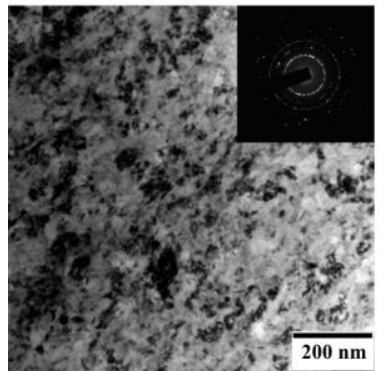

g) $v_{b}=6 \mathrm{~m} / \mathrm{min}$

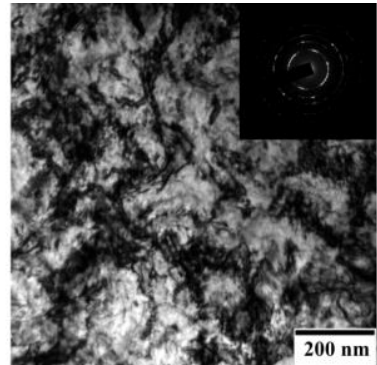

b) $v_{b}=11 \mathrm{~m} / \mathrm{min}$

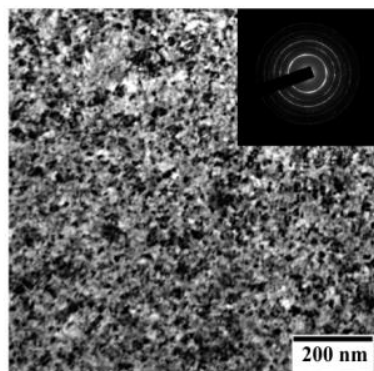

e) $v_{b}=11 \mathrm{~m} / \mathrm{min}$

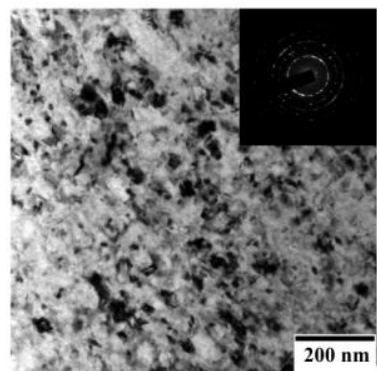

h) $v_{b}=11 \mathrm{~m} / \mathrm{min}$

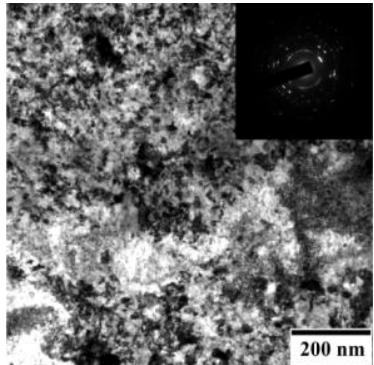

c) $v_{b}=20 \mathrm{~m} / \mathrm{min}$

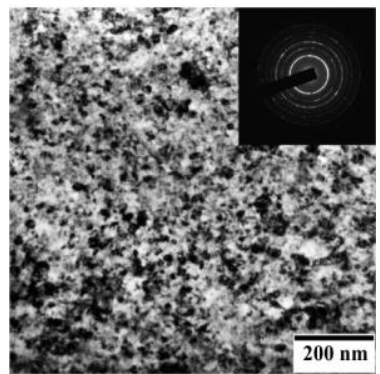

f) $v_{b}=20 \mathrm{~m} / \mathrm{min}$

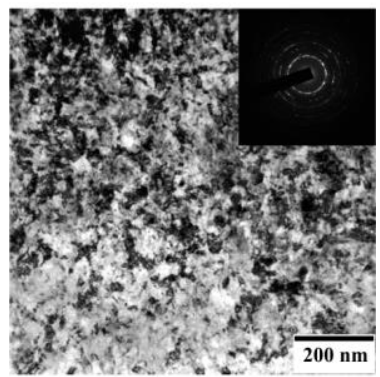

i) $v_{b}=20 \mathrm{~m} / \mathrm{min}$

Fig. 5 Transmission electron microscopy of the surface layer in the paths obtained at loading repetition factors of $4.2(\mathrm{a}, \mathrm{b}, \mathrm{c}) ; 6.3(\mathrm{~d}, \mathrm{e}, \mathrm{f})$ и $12.5(\mathrm{~g}, \mathrm{~h}, \mathrm{i})$. 
The microstructural analysis of the foils showed that the nanocryslalline structure evolves with various dispersion degrees depending on different combinations of the parameters of the sliding velocity and loading repetition factor that are under study. In addition to it, a relation can be traced between the dispersion of the structure being formed and the shear strain intensity in the material of the surface layer. For instance, a composite UFG- and nanocrystalline structure develops at a sliding velocity of $6 \mathrm{~m} / \mathrm{min}$ and shear strain intensities below 2.8 regardless of loading repetition factor values (Fig. 5, a, $\mathrm{d}, \mathrm{g}$ ). In the cases when the velocity is $11 \mathrm{~m} / \mathrm{min}$ and the shear strain intensity reaches $3.75 \ldots 4$. A homogeneous nanocrystalline structure is observed in the surface layer; it is proved by a circular shape of the interferogrammas (Fig. 5, b, e, h). If the velocity is increased to $20 \mathrm{~m} / \mathrm{min}$, the dispersion of the structure significantly decreases as a result of the shear strain intensity going down (Fig. 5, c, f, i).

\section{CONCLUSIONS}

Notwithstanding considerable differences in the shear strain intensity and the shear strain rate, each combination of the parameters of the loading repetition factor and indentor sliding velocity within the framework of the research meets the conditions necessary for a nanocrystalline structure to form $\left(\varepsilon \geq 2, \dot{\varepsilon} \geq 10^{2} \mathrm{~s}^{-1}\right)$. The research proves that higher values of the shear strain intensity and rate are achieved in nanostructuring burnishing. This appears to be stimulating for obtaining higher dispersion degrees of the grain structure and ensures formation of a homogeneous surface layer. The results thus obtained explain the differences in the microhardness of nanostructured surfaces occurring in the cases when the sliding velocity is altered; these differences were found earlier in the papers [13, 15].

It is worth mentioning that the proposed procedure enables us only to determine certain mean values of the shear strain intensity and the shear strain rate in the edged layer. Actually, the shear strain intensity is expected to be higher on the surface and to gradually go down reaching zero on the boundary of the edged layer. From the point of view of controlling nanostructuring the knowledge of how the shear strain intensity and the plastic shear strain rate are distributed across the edged layer is of great scientific value. To determine it experimentally it is necessary that the present procedure should be further perfected.

\section{REFERENCES}

1. Papsev, D.D., 1978, Finishing \& hardening with cold working, Mechanical Engineering, pp 10-15.

2. Korzynski, M., Pacana, A., 2010, Centreless burnishing and influence of its parameters on machining effects, Journal of Materials Processing Technology, 210(9), pp. 1217-1223.

3. Maximov, J.T., Anchev, A.P., Duncheva, G.V., Ganev, N., Selimov, K.F., 2016, Influence of the process parameters on the surface roughness, micro-hardness, and residual stresses in the slide burnishing of highstrength aluminium alloys, Journal of the Brazilian Society of Mechanical Sciences and Engineering, 39(8), pp. 3067-3078.

4. Hamadache, H., Laouar, L., Zeghib, N.E., Chaoui, K., 2006 Characteristics of Rb40steel superficial layer under ball and roller burnishing, Journal of Materials Processing Technology, 180(1), pp. 130-136.

5. Shiou, F.J., Cheng, C.H., 2008, Ultra-precision surface finish of NAK80 mould tool steel using sequential ball burnishing and ball polishing processes, Journal of Materials Processing Technology, 201(1-3), pp. 554-559.

6. Shiou, F.J., Chuang, C.H., 2010, Precision surface finish of the mold steel PDS5 using an innovative ball burnishing tool embedded with a loading cell, Precision Engineering, 34, pp. 76-84. 
7. Przybylski, W., 1987, Burnishing Technology, Science Publishing Home, Warszawa (in Polish).

8. Kuznetsov, V.P., Smolin, I.Yu., Dmitriev, A.I., Konovalov, D.A., Makarov, A.V., Kiryakov, A.E., Yurovskikh, A.S., 2013, Finite element simulation of nanostructuring burnishing, Physical Mesomechanics, 16(1), pp. 62-72.

9. Kuznetsov, V.P., Makarov, A.V., Psakhie, S.G., Savrai, R.A., Malygina, I.Yu., Davydova, N.A., 2014, Tribological aspects in Nanostructuring burnishing of structural steels, Physical Mesomechanics, 17(4), pp. 250-264.

10. Selliger, G., Stephan, J., Lange, S., 2000, Hydroadhesive gripping by using Peltier effect, ASME International Mechanical Engineering Congress \& Exposition (IMECE), pp. 3-8.

11. Kuznetsov, V.P., Tarasov, S.Yu., Dmitriev, A.I., 2015, Nanostructuring burnishing and subsurface shear instability, Journal of Materials Processing Technology, 217, pp. 327-335.

12. Dmitriev, A.I., Kuznetsov, V.P., Nikonov, A.Yu., Smolin, I.Yu., 2014, Modelling of nanostructuring burnishing on different scales, Physical Mesomechanics, 17(4), pp. 6-13.

13. Kuznetsov, V.P., Tarasov, S.Yu., Dmitriev, A.I., 2014, Identification of conditions for nanostructuring burnishing and subsurface shear instability, International Conference on Physical Mesomechanics of Multilevel Systems 2014, 3-5 September 2014, Tomsk, Russia - AIP Conf.Proc, 1623, pp. 331-334.

14. Kuznetsov, V.P., Smolin, I.Yu., Dmitriev, A.I., Tarasov, S.Yu., Gorgots,. V.G., 2016, Toward control of subsurface strain accumulation in nanostructuring burnishing on thermostrengthened steel, Surface and Coatings Technology, 285, pp. 171-178.

15. Kuznetsov, V.P., Skorobogatov, A.S., Gorgots, V.G., Yurovskikh, A.S., 2016, The Analysis of speed increase perspectives of nanostructuring burnishing with heat removal from the tool, IOP Conf. Series: Materials Science and Engineering, 124, 012127.

16. Kuznetsov, V.P., Skorobogatov, A.S., Gorgots, V.G., 2015, Mathematical model of thermal physics of the dualcycle cooling system of the tool for pieces nanostructuring burnishing, Applied Mechanics and Materials, 770, pp. $449-455$.

17. Zhao, J., Xia, W., Li, N., Li, F., 2014, A gradient nano/micro-structured surface layer on copper induced by severe plasticity roller burnishing, Transactions of Nonferrous Metals Society of China, 24, pp. 441-448.

18. Roland, T., Retraint, D., Lu, K., Lu, J., 2006, Fatigue life improvement through surface nanostructuring of stainless steel by means of surface mechanical attriction treatment, Scripta Materiala, 54, pp. 1949-1954.

19. Huang, B., Kayank, Y., sun, Y., Jawahir, I.S., 2015, Surface layer modification by cryogenic burnishing of al 7075-t7451 alloy and validation woth fem-based burnishing model, Procedia CIRP, 31, pp. 1-6.

20. Azushima, A., Kopp, R., Korhonen, A., Yang, D.Y., Micari, F., Lahoti, G.D., Groche, P., Yanagimoto, J., Tsuji, N., Rosochowski, A., Yanagida, A., 2008, Severe plastic deformation (SPD) processes for metals, CIRP Annals - Manufacturing Technology, 57, pp. 716-735.

21. Gleiter, H., 1991, Nanocrystalline Materials, Advanced Structural and Functional Materials, pp. 1-37.

22. Heilmann, I., Clark, W.A., Rigney, D.A., 1983, Orientation determination of subsurface cells generated by sliding, Acta Metallurgica, 31(8), pp. 1293-1305.

23. Segal, V.M., 2011, Fundamentals and Engineering of Severe Plastic Deformation, Nova Science Pub Inc, $542 \mathrm{p}$

24. Zhao, X., Yang, X., Jing, T., 2012, Effect of initial microstructure on warm deformation behavior of 45 steel, Journal of Iron and Steel Research International, 19, pp. 75-78.

25. Farghadany, E., Zarei-Hanzaki, A., Abedi, H.R., Dietrich, D., Lampke, T., 2014, The strain accommodation in Ti-28Nb-12Ta-5Zr alloy during warm deformation, Materials Science and Engineering: A, 592, pp. 57-63.

26. Valiev, R., Islamgaliev, R., Alexandrov, I., 2000, Bulk nanostructured materials from severe plastic deformation, Progress in Materials Science, 45, pp. 103-189. 